\title{
A RARE CASE OF CLEAR CELL SARCOMA OF TENDONS
}

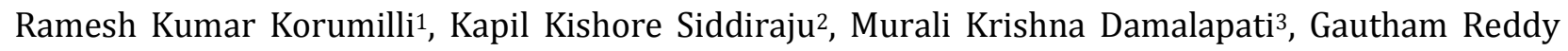
Ginjala ${ }^{4}$

\section{HOW TO CITE THIS ARTICLE:}

Ramesh Kumar Korumilli, Kapil Kishore Siddiraju, Murali Krishna Damalapati, Gautham Reddy Ginjala. "A rare case of Clear Cell Sarcoma of Tendons". Journal of Evolution of Medical and Dental Sciences 2014; Vol. 3, Issue 01, January 06; Page: 30-31.

ABSTRACT: Clear cell sarcoma of tendons \& aponeuroses, is a rare malignancy derived from neural crest cells. It commonly presents in young adults in extremities. It is usually a high grade tumor with poor survival rates. Grossly, the tumor is circumscribed with a histologic pattern of uniform polygonal to fusiform cells with clear to pale eosinophilic cytoplasm divided into variably sized clusters by fibrous septa. Immunohistochemistry reveals neopalstic cells which are positive for HMB-45 \& react with antibody against S-100 protein. Mainstay treatment remains wide excision of tumor. The role of chemotherapy \& radiotherapy are reported to be limited. We report this case in view of its rarity.

KEY WORDS: Clear cell sarcoma, Tendons, Aponeurosis, S-100 protein, melanoma.

CASE REPORT: A 35 year old female patient presented to surgical out-patient department with a circumscribed swelling in front of right wrist of 6 months ${ }^{1}$. She was a manual laborer by occupation. She gave history of recent rapid growth \& dull dragging pain for the past 1 month. There was no history of fever, trauma \& no loss of weight / appetite.

On examination, patient was moderately built with normal vital signs. A solitary circumscribed growth was seen over flexor aspect of right wrist joint measuring about $2.5 \mathrm{~cm}$ by 3 $\mathrm{cm}$. Local raise of temperature was noted. Consistency was firm. Swelling was Non-tender with restricted mobility. In the right hand distal to the growth, there was no neurovascular deficiency. No regional lymphadenopathy noted. No similar swellings were noted anywhere else in the body. Chest \& abdomen were clinically normal. No hepato-splenomegaly was present.

A clinical diagnosis of soft tissue tumor was made with the differential diagnosis of sarcoma / malignant melanoma. ${ }^{2}$ FNAC of the swelling reported as "Spindle cell lesion with altered NuclearCytoplasmic ratio with binucleate cells \& myxoid areas". Patient was planned for surgery \& complete excision of tumor was done. Histopathologist reported possibilities of a) Clear Cell Sarcoma of Tendon \& Aponeurosis b) Biphasic pattern of synovial sarcoma.

Immunohistochemistry showed positive $(+++)$ for $S-100^{3} \&$ negative for both EMA \& Desmin suggestive of Clear Cell Sarcoma of Tendon \& Aponeurosis. ${ }^{4}$

Patient was discharged after 1 week came for review after $1^{\text {st }}$ and 2 nd months without any local recurrence $\&$ had no complaints.

DISCUSSION: Clear cell sarcoma of tendons is a rare malignancy. The differential diagnosis of such a tumor of tendons in an extremity includes- Paragangliomas like -Dermal melanocytic tumor,Clear cell Myomelanocytic tumor, Malignant Melanoma, Malignant peripheral nerve sheath tumor and Synovial sarcoma. 
Usually treatment of Clear cell sarcoma of tendons involves wide excision of tumor. In this case patient was not willing for wide excision. As Chemotherapy and Radiotherapy have limited role patient was advised periodic monthly follow up. After second follow up visit patient was found to have no symtoms and no local recurrence.

\section{REFEERENCES:}

1. Abell MR, Hart WR, Olson JR (1970) Tumors of the peripheral nervous system. Hum Pathol 1:503-551.

2. Clark Raynor A, Vargas-Cortes F, Alexander RW, Bingham HG (1979) Clear cell sarcoma with melanin pigment: a possible soft-tissue variant of malignant melanoma. J Bone It Surg 61:276280.

3. Nakajima T, Watanabe S, Sato Y, Kameya T, Shimosato Y (1981) Immunohistochemical demonstration of S-100 protein in human malignant melanoma and pigmented nevi. Gann 72:335-336.

4. Mukherjee AK, Gupta S (1978) Clear-cell sarcoma of tendons and aponeuroses - a case report. Indian J Can 15:69-71.

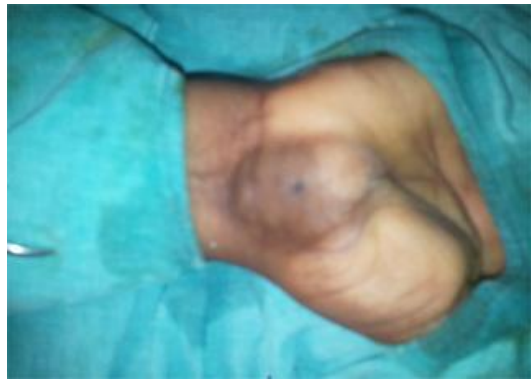

Pre-operative Clinical

Photograph

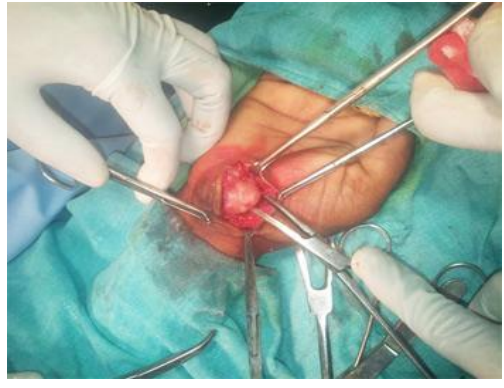

Intra-operative Clinical Photograph:

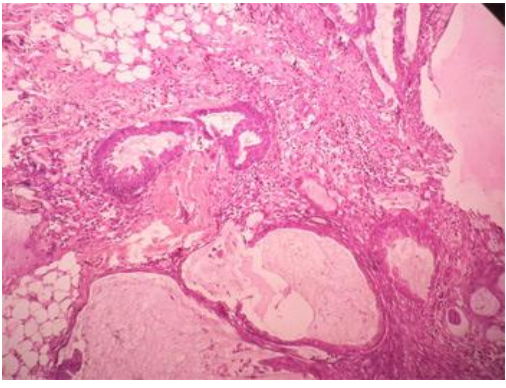

Microphotograph of the Excised tumor:

\section{AUTHORS:}

1. Ramesh Kumar Korumilli

2. Kapil Kishore Siddiraju

3. Murali Krishna Damalapati

4. Gautham Reddy Ginjala

\section{PARTICULARS OF CONTRIBUTORS:}

1. Professor, Department of Surgery, SVS Medical College \& Hospital, Mahabubnagar, Andhra Pradesh, India.

2. Post Graduate, Department of General Surgery, SVS Medical College \& Hospital, Mahabubnagar, Andhra Pradesh, India.

3. Post Graduate, Department of General Surgery, SVS Medical College \& Hospital, Mahabubnagar, Andhra Pradesh, India.
4. Assistant Professor, Department of General Surgery, SVS Medical College \& Hospital, Mahabubnagar, Andhra Pradesh, India.

\section{NAME ADDRESS EMAIL ID OF THE CORRESPONDING AUTHOR:}

Dr. Ramesh Kumar Korumilli, Plot No. 70, Gruha Laxmi Colony, Old Kakaguda, Secunderbad, Andhra Pradesh, PIN - 500009.

Email-rameshkorumilli@gmail.com

Date of Submission: 13/12/2013.

Date of Peer Review: 14/12/2013.

Date of Acceptance: 23/12/2013.

Date of Publishing: 01/01/2014 